\title{
Light Absorption by Brown Carbon over the South-East Atlantic Ocean
}

Lu Zhang ${ }^{1}$, Michal Segal-Rozenhaimer ${ }^{1,2}$, Haochi Che ${ }^{1}$, Caroline Dang ${ }^{3,4}$, Arthur J. Sedlacek III ${ }^{5}$, Ernie

R. Lewis ${ }^{5}$, Amie Dobracki ${ }^{6}$, Jenny P.S. Wong ${ }^{7}$, Paola Formenti ${ }^{8}$, Steven G. Howell ${ }^{9}$, Athanasios Nenes ${ }^{10,11}$

${ }^{1}$ Department of Geophysics, Tel Aviv University, Tel Aviv, Israel

${ }^{2}$ Bay Area Environmental Research Institute, NASA Ames Research Center, Moffett Field, California, USA

${ }^{3}$ NASA Ames Research Center, Moffett Field, California, USA

${ }^{4}$ Universities Space Research Association, Columbia, Maryland, USA,

${ }^{5}$ Brookhaven National Laboratory, Upton, New York, USA

$10{ }^{6}$ Rosenstiel School of Marine and Atmospheric Science, University of Miami, Miami, USA

${ }^{7}$ Mount Allison University, New Brunswick, CA

${ }^{8}$ Université de Paris and Univ Paris Est Creteil, CNRS, LISA, Paris, France

${ }^{9}$ University of Hawaii at Manoa, Department of Oceanography, Honolulu, USA

${ }^{10}$ Laboratory of Atmospheric Processes and their Impacts, School of Architecture, Civil \& Environmental

15 Engineering, École Polytechnique Fédérale de Lausanne, Switzerland

${ }^{11}$ Center for Studies of Air Quality and Climate Change, Institute of Chemical Engineering Sciences, Foundation for 20 Research and Technology Hellas, Greece

Correspondence to: Lu Zhang (luzhang@mail.tau.ac.il)

Abstract. Biomass burning emissions often contain brown carbon $(\mathrm{BrC})$, which represents a large family of light-

absorbing organics that are chemically complex and therefore difficult to estimate their absorption of incoming solar radiation, resulting in large uncertainties in the estimation of the global direct radiative effect of aerosols Here we investigate the contribution of $\mathrm{BrC}$ to the total light absorption of biomass burning aerosols over the South-East Atlantic Ocean with different optical models utilizing a suite of airborne measurements from the ORACLES 2018 campaign by introducing an effective refractive index of black carbon $(\mathrm{BC}), m_{\mathrm{eBC}}=n_{\mathrm{eBC}}+\mathrm{i} k_{\mathrm{eBC}}$, that accounts for all possible absorbing components at $660 \mathrm{~nm}$ wavelength to facilitate the attribution of absorption at shorter wavelengths.

Most values of the imaginary part of the refractive index, $k_{\mathrm{eBC}}$, were larger than those commonly used for $\mathrm{BC}$ from biomass burning emissions, suggesting contributions from absorbers beyond $\mathrm{BC}$ at $660 \mathrm{~nm}$. The TEM-EDX single particle analysis further suggests that these long-wavelength absorbers might include iron oxides, as iron

30 is found to be present only when large values of $k_{\mathrm{eBC}}$ are derived. Using this effective $\mathrm{BC}$ refractive index, we find that the contribution of $\mathrm{BrC}$ to the total absorption at $470 \mathrm{~nm}\left(R_{\mathrm{BrC}, 470}\right)$ ranges from $\sim 5-15 \%$, with the organic aerosol mass absorption coefficient $(\mathrm{MACOA,470})$ at this wavelength ranging from $0.25 \pm 0.34 \mathrm{~m}^{2} \mathrm{~g}^{-1}$ to $0.43 \pm 0.12 \mathrm{~m}^{2} \mathrm{~g}^{-1}$. The core-shell model yielded much higher estimates of MACOA,470 and $\mathrm{R}_{\mathrm{BrC}, 470}$ than 
homogeneous mixing models, underscoring the importance of model treatment. Another key finding was that estimates of the $\mathrm{BrC}$ contribution at $470 \mathrm{~nm}$ from the commonly used AAE (absorption Ångström exponent) attribution method $(<5 \%)$ are much lower than the $\mathrm{BrC}$ contribution estimates $\left(\mathrm{R}_{\mathrm{BrC}, 470)}\right)$ using our new methodology that accounts for contributions from both $\mathrm{BrC}$ and non-carbonaceous, long-wavelength absorbers, such as magnetite. Thus, it is recommended that application of any optical properties-based attribution method use absorption coefficients at the longest possible wavelength to minimize the influence of $\mathrm{BrC}$ at the long wavelength and to account for potential contributions from other absorbing materials.

\section{Introduction}

Black carbon $(\mathrm{BC})$ and brown carbon $(\mathrm{BrC})$ are two main light-absorbing carbonaceous aerosols that

10 play a significant role in Earth's radiative forcing and climate (Bond et al., 2013; Laskin et al., 2015; Brown et al., 2018). BC is the principal atmospheric particulate absorber that absorbs strongly over the entire solar spectrum (Bond and Bergstrom, 2006). Biomass burning (BB) contributes approximately $2 / 3$ of the global primary organic aerosol (OA) budget, which currently most climate models treat as "white carbon" that only scatters and does not absorb light (Bond et al., 2013). However, studies show that BB OA contains a substantial amount of BrC, which predominantly absorbs at short visible and near-UV wavelengths (Chen and Bond, 2010; Lack et al., 2012; Saleh et al., 2014; Taylor et al., 2020). Feng et al. (2013) found that the absorption of BrC can shift BB direct radiative forcing to positive values. The contribution of $\mathrm{BrC}$ to the total absorption by carbonaceous aerosols is estimated to be $\sim 20-50 \%$ with a global radiative effect of $\sim 0.03-0.6 \mathrm{~W} \mathrm{~m}^{-2}$ (Kirchstetter and Thatcher, 2012; Wang et al., 2013; Feng et al., 2013; Saleh et al., 2015; Jo et al., 2016). However, values reported by these studies are subject to substantial uncertainties, and investigations of $\mathrm{BrC}$ properties are still very much in a developmental stage. Thus, in order to realize a substantive reduction in the uncertainty, better attribution of $\mathrm{BrC}$ light absorption must be first accomplished.

To date, several methods have been employed to investigate the light absorption of BrC. The AAE (absorption Ångström exponent) attribution method utilizes the different spectral dependences of the absorption by $\mathrm{BC}$ and $\mathrm{BrC}$ to determine the contribution from $\mathrm{BrC}$ at short wavelengths (Lack and Langridge, 2013; Wang et al., 2018a; Taylor et al., 2020). Most earlier studies assumed the AAE of BC (AAE $\mathrm{BC}_{\text {) }}$ to be unity, although this assumption may introduce large uncertainties (Lack and Langridge, 2013) because AAEBC varies with size, mixing state, and wavelength (Lack and Cappa, 2010; Fig. 2 in Liu et al., 2015; Liu et al., 2018). Revised methods with more realistic values of $\mathrm{AAE}_{\mathrm{BC}}$ have been proposed, such as using the $\mathrm{AAE}$ from two long-visible wavelengths (Taylor et al., 2020) or that from the Mie model (Wang et al., 2018a). A major drawback of these methods is that they are suitable only for mixtures of $\mathrm{BC}$ and $\mathrm{BrC}$, and if other absorbing materials are present, such as dusts, more detailed information is needed to account for their contribution to light absorption at the longer 
wavelengths. Another methodology involves measuring the absorption of organics that have been extracted with either an organic solvent or water and represents, thus far, the only way to directly measure $\mathrm{BrC}$ absorption (Wong et al., 2019). The drawback to this approach is that not all organics can be extracted with one or two solvents, as highlighted by the work of Chen and Bond (2010), who reported extraction efficiencies of $\sim 70 \%$ in water and $\sim 90 \%$ in methanol. This inability to extract all organics means that insoluble organic substances remain unknown since they are not measured. This, in turn, could lead to cases where the absorption properties of the extracted organics might be different from those derived from in situ measurements. In addition, this method is carried out offline and requires elaborate laboratory analysis. Still another approach to estimate the absorption of $\mathrm{BrC}$ is through optical closure, determine the $\mathrm{BrC}$ absorption as the difference of the total measured absorption and that of BC calculated using Mie theory (Saleh et al., 2014; Liu et al., 2015). In this approach, the accuracy of BrC absorption relies heavily on the accuracy of BC absorption calculation. Values commonly used for the refractive index of $\mathrm{BC}\left(m_{\mathrm{BC}}\right)$ from $\mathrm{BB}$ emissions in these calculations have ranged from $1.5+0.3 \mathrm{i}$ to $1.95+0.79 \mathrm{i}$ (Liu et al., 2015; Chylek et al., 2019; Taylor et al., 2020), which will lead to large differences in BC absorption simulation results (Taylor et al., 2020). To date there is no consensus on the best value of $m_{\mathrm{BC}}$. Another factor influencing the $\mathrm{BC}$ absorption calculation, and hence the estimated $\mathrm{BrC}$ absorption, is the mixing state of $\mathrm{BC}$ and non- $\mathrm{BC}$ components within particles. Liu et al. (2015) used the core-shell (CS) Mie model and Rayleigh-Debye-Gans approximation to investigate the effect of $\mathrm{BC}$ microphysics on the estimation of $\mathrm{BrC}$ absorption and found it to be highly sensitive to the model treatment. Saleh et al. (2014) compared internal and external mixtures of BC and $\mathrm{BrC}$ and found internally mixed cases yielded smaller $\mathrm{BrC}$ absorption than externally ones. Similar to the AAE attribution method, the presence of absorbing materials other than $\mathrm{BC}$ and $\mathrm{BrC}$ can lead to errors in the attribution of $\mathrm{BrC}$ absorption. For example, light absorbing $\mathrm{FeOx}$ was found to be common in field studies, especially for BB emissions (Ito et al., 2018), yet few studies perform measurements of size distributions and chemical composition by these particle types, making it difficult to separate their contribution to the total absorption from that of $\mathrm{BrC}$.

The savannah regions in Africa experience widespread annual BB events from July to October, which are estimated to account to approximately $1 / 3$ of global BB emissions (van der Werf et al., 2010). These aerosols are transported westward over the South-East Atlantic, making this region an ideal natural laboratory for investigating the absorption of $\mathrm{BrC}$ from $\mathrm{BB}$ emissions. In this study, we estimate the absorption of $\mathrm{BrC}$ using the optical closure method utilizing in-situ aircraft measurements and offline single particle analysis from the ORACLES (ObseRvations of Aerosols above CLouds and their intEractionS) 2018 campaign (Redemann et al., 2020). An effective refractive index of $\mathrm{BC}\left(m_{\mathrm{eBC}}\right)$, which attempts to capture the absorption of all possible absorbing components at $660 \mathrm{~nm}$, is introduced to facilitate the absorption attribution at shorter wavelengths. The core-shell model and homogeneous models are applied and compared in this study. The range of values of the 
organic aerosol mass absorption coefficient $\left(\mathrm{MAC}_{\mathrm{OA}, 470}\right)$ and contribution of $\mathrm{BrC}$ to the total absorption at 470 $\mathrm{nm}\left(R_{\mathrm{BrC}, 470)}\right)$ using the optical closure method are obtained.

\section{Methods}

\subsection{Site and Instrumentation}
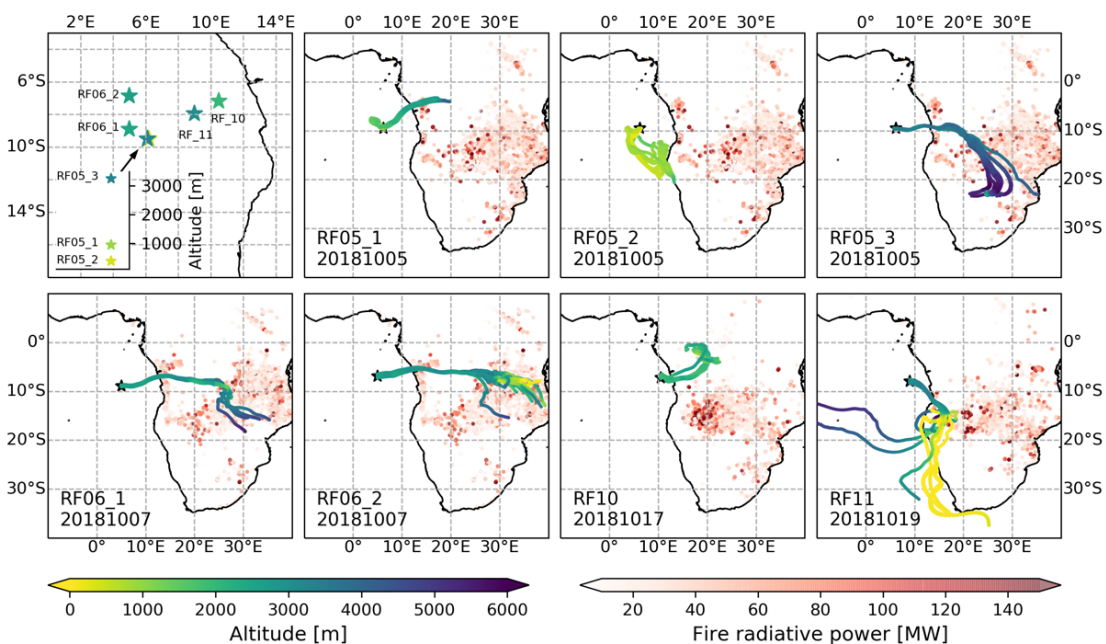

Figure 1: (upper left panel) overview of the flight locations during ORACLES 2018 investigated in this study, and (all other panels) 7-day back trajectories and fire radiative power (FRP) from MODIS 6 Collection Active Fire Detections (MCD14ML) at the end day of the trajectory (only data with confidence $>50 \%$ are used here).

ORACLES was a three-year NASA-funded field campaign to investigate the influence of BB emissions from southern Africa on regional and global climate (Redemann et al., 2020). We investigated aerosol optical properties during seven research flights (RF) from the ORACLES 2018 campaign (Fig. 1): RF05_1, RF05_2, RF05_3, RF6_1, RF6_2, RF10, and RF11. The specifications for each flight can be found in Table 1 in Dang et al. (2021). These flights were chosen as they provided investigations of aerosol properties from the marine boundary layer (MBL) and in the free troposphere, from relatively aged aerosols to highly aged aerosols, and are comprehensive in online and offline measurements with few missing data. RF05_1 occurred in mixed cloud and aerosol layer at an altitude of $\sim 1 \mathrm{~km}, \mathrm{RF} 0522$ was within the MBL at an altitude of $\sim 380 \mathrm{~m}$, the others were in the aerosol layer above the MBL at an altitude equal to or greater than $2 \mathrm{~km}$. The aging time is taken as the first interception of back trajectories with fires; note this age is strictly minimum age as air can get repeated injections of smoke. The age was estimated to be $\sim 155 \mathrm{~h}$ for RF05_1 and $\sim 40 \mathrm{~h}$ for RF05_3, RF6_1, RF6_2, RF10, and

RF11. The age of RF05_2 was uncertain as its 7-day back trajectories were within the MBL and did not reach the 
fires, but based on the result from the Weather Research and Aerosol Aware Microphysics (WRF-AAM) model, it was $\sim 9$ h older than RF05_1, and thus the most aged among all samples.

Particle properties measured were non-refractory submicron aerosol composition from an Aerosol Mass Spectrometer (AMS), mass concentrations of refractory BC and mixing state of BC-containing particles from a Single Particle Soot Photometer (SP2), particle number size distribution (PNSD) from an Ultra-High-Sensitivity Aerosol Spectrometer (UHSAS) and Aerodynamic Particle Sizer (APS), light absorption at 470, 530, and $660 \mathrm{~nm}$ from a Particle Soot Absorption Photometer (PSAP), light scattering at 450, 550, and $700 \mathrm{~nm}$ from a nephelometer (Neph), and particle morphology and elemental composition from filter samples that were analysed by a transmission electron microscopy (TEM) coupled with energy dispersive X-ray (EDX). The light absorption from

10 the PSAP was corrected using the wavelength-average correction scheme following Virkkula (2010) and Pistone et al. (2019). All instruments were mounted in the NASA P-3 aircraft and operated under dry conditions except for the Neph, whose humidity is not controlled. Data for BC mass concentration less than $0.1 \mu \mathrm{g} / \mathrm{m}^{3}$ or absorption coefficient at $660 \mathrm{~nm}$ less than $1.5 \mathrm{Mm}^{-1}$ were not included. Measurements were averaged to $10 \mathrm{~s}$ and adjusted to STP values at $273.15 \mathrm{~K}$ and $1013 \mathrm{hPa}$. More details of the instrumentation are provided in Section $\mathrm{S} 1$ of the supplemental information.

\subsection{Optical Models}

From the TEM images, most of the particles were found to be nearly spherical, with $>70 \%$ of the particles having aspect ratios $<1.5$; therefore, we applied Mie theory in our optical simulations. We investigated the sensitivity of our closure simulations to four different models - the ideal core-shell (CS) model and three homogeneous mixing models: 1) the volume mixing (VM) model, 2) the Maxwell-Garnett (MG) model, and 3) the Bruggemann (BG) model. We did not investigate the externally mixing model, as our TEM analysis showed that most of the particles were internally mixed (Dang et al., 2021).

In our optical closure, particles were separated into BC-containing particles and $\mathrm{BC}$-free particles, whose size distributions were calculated with the PNSD of all particles from the UHSAS and APS, and BC 2-D size and mixing state (i.e. coating thickness) distribution of BC-containing particles from the SP2. We applied the aforementioned four models to BC-containing particles. Detailed descriptions and inputs of all four models can be found in Section S2 in the supplement. We assumed that the non-BC components in both populations were homogeneously well mixed and calculated the refractive index of the mixture, $m_{\mathrm{BC}-\text {-free, }}$ with the VM rule, which assumes that the index of refraction of the mixture is the sum of the volume-weighted indices of refraction of the

30 individual components. The mass concentrations of $\mathrm{SO}_{4}^{2-}, \mathrm{NO}_{3}^{-}, \mathrm{NH}_{4}^{+}$, and $\mathrm{Cl}^{-}$measured by AMS were converted to those of inorganic salts using the simplified ion-pairing scheme proposed by Gysel et al. (2007), modified as follows: 


$$
\begin{aligned}
& n_{N H_{4} C l}^{m o l}=n_{C l^{-}}^{m o l} \\
& n_{N H_{4} N O_{3}}^{m o l}=\min \left(n_{N O_{3}^{-}}^{m o l}, n_{N H_{4}^{+}}^{m o l}-n_{C l^{-}}^{m o l}\right) \\
& n_{N H_{4} \mathrm{HSO}_{4}}^{m o l}=\max \left(0, \min \left(2 n_{S O_{4}^{2-}}^{m o l}-n_{N H_{4}^{+}}^{m o l}+n_{N O_{3}^{-}}^{m o l}+n_{C l^{-}}^{m o l}, n_{N H_{4}^{+}}^{m o l}-n_{N O_{3}^{-}}^{m o l}-n_{C l^{-}}^{m o l}\right)\right) \\
& n_{\left(N H_{4}\right)_{2} S O_{4}}^{m o l}=\max \left(0, \min \left(n_{S O_{4}^{2-}}^{m o l}, n_{N H_{4}^{+}}^{m o l}-n_{N O_{3}^{-}}^{m o l}-n_{C l^{-}}^{m o l}-n_{S O_{4}^{2-}}^{m o l}\right)\right) \\
& n_{K N O_{3}}^{m o l}=\max \left(0, \min \left(n_{N O_{3}^{2}}^{m o l}, n_{N H_{4}^{+}}^{m o l}-n_{N O_{3}^{3}}^{m o l}-n_{C l^{-}}^{m o l}-2 n_{S O_{4}^{2-}}^{m o l}\right)\right) \\
& n_{\mathrm{KSO}_{4}}^{m o l}=\max \left(0, \min \left(n_{S O_{4}^{2-}}^{m o l}, n_{S O_{4}^{2-}}^{m o l}-n_{N H_{4}^{+}}^{m o l}+n_{C l^{-}}^{m o l}+n_{N O_{3}^{-}}^{m o l}\right)\right)
\end{aligned}
$$

where $n^{\text {mol }}$ represents the number of moles. As potassium salts are the most frequently detected salts from TEMEDX analysis (Dang et al., 2021), the residual anions were assumed to be combined with potassium, i.e. $\mathrm{KNO}_{3}$ and $\mathrm{K}_{2} \mathrm{SO}_{4}$. Note that a small fraction of $\mathrm{NO}_{3}^{-}$and $\mathrm{SO}_{4}^{2-}$ detected by AMS might be organic and thus lack an accompanying cation. Densities of the various salts and OA used to convert the mass concentrations to volume concentrations were taken from Kuang et al. (2020; Table 1) and Liu et al. (2015b). Thus, $m_{\mathrm{BC}-\text { free }}$ is calculated as

$$
m_{B C-\text { free }}=\left(\sum_{i=\text { salts }} m_{i} * V_{i}+m_{O A} * V_{O A}\right) /\left(\sum_{i=\text { salts }} V_{i}+V_{O A}\right)
$$

where $m_{\mathrm{i}}$ and $V_{\mathrm{i}}$ represent the refractive indices and volumes of aforementioned salts; $m_{\mathrm{OA}}$ and $V_{\mathrm{OA}}$ are those for OA. The refractive indices of salts are taken from Table 1 in Kuang et al. (2020). The quantity $m_{\mathrm{BC}-\text {-free }}$ is assumed to be the same value for both $\mathrm{BC}$-free particles and the non-BC component in $\mathrm{BC}$-containing particles. The effective refractive indices for the VM, MG, and BG models can then be obtained by the corresponding mixing rules (Section $\mathrm{S} 2$ in the supplement). The density of $\mathrm{BC}$ is assumed to be $1.8 \mathrm{~g} \mathrm{~cm}^{-3}$ (Bond and Bergstrom, 2006; Liu et al., 2017). The refractive indices of BC and OA will be presented in the following section.

\subsection{Optical calculation procedure}


https://doi.org/10.5194/acp-2021-1000

Preprint. Discussion started: 28 January 2022

(c) Author(s) 2022. CC BY 4.0 License.

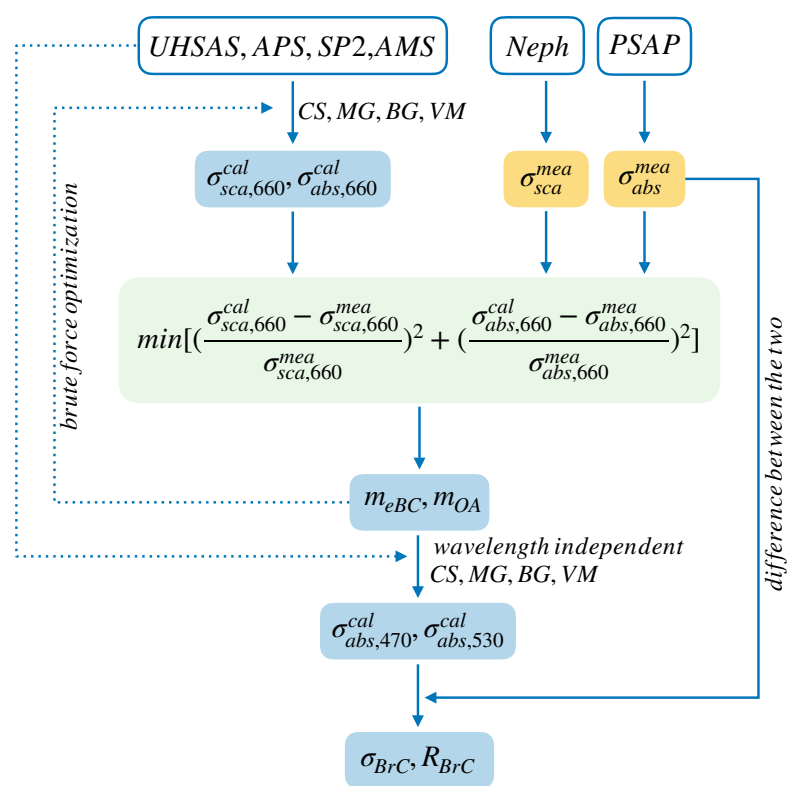

Figure 2: Schematic diagram of the iterative derivation of $\mathrm{BrC}$ absorption attribution performed in this study. Cells in white, yellow, and blue represent instrument, measurements, and calculations, respectively. The green box is the optimization step used to determine the values of the effective refractive index of $\mathrm{BC}, m_{\mathrm{eBC}}$ and the refractive index of $\mathrm{OA}, m_{\mathrm{OA}}$, once the deviation of measured and calculated scattering and absorption coefficients at $660 \mathrm{~nm}$ are minimized. $m_{\mathrm{eBC}}$ and $m_{\mathrm{OA}}$ are held constant at investigated wavelengths, i.e. 470,530 , and $660 \mathrm{~nm}$. The imaginary part of the refractive index of $\mathrm{OA}, k_{\mathrm{OA}}$, was restricted to 0 in this calculation. 

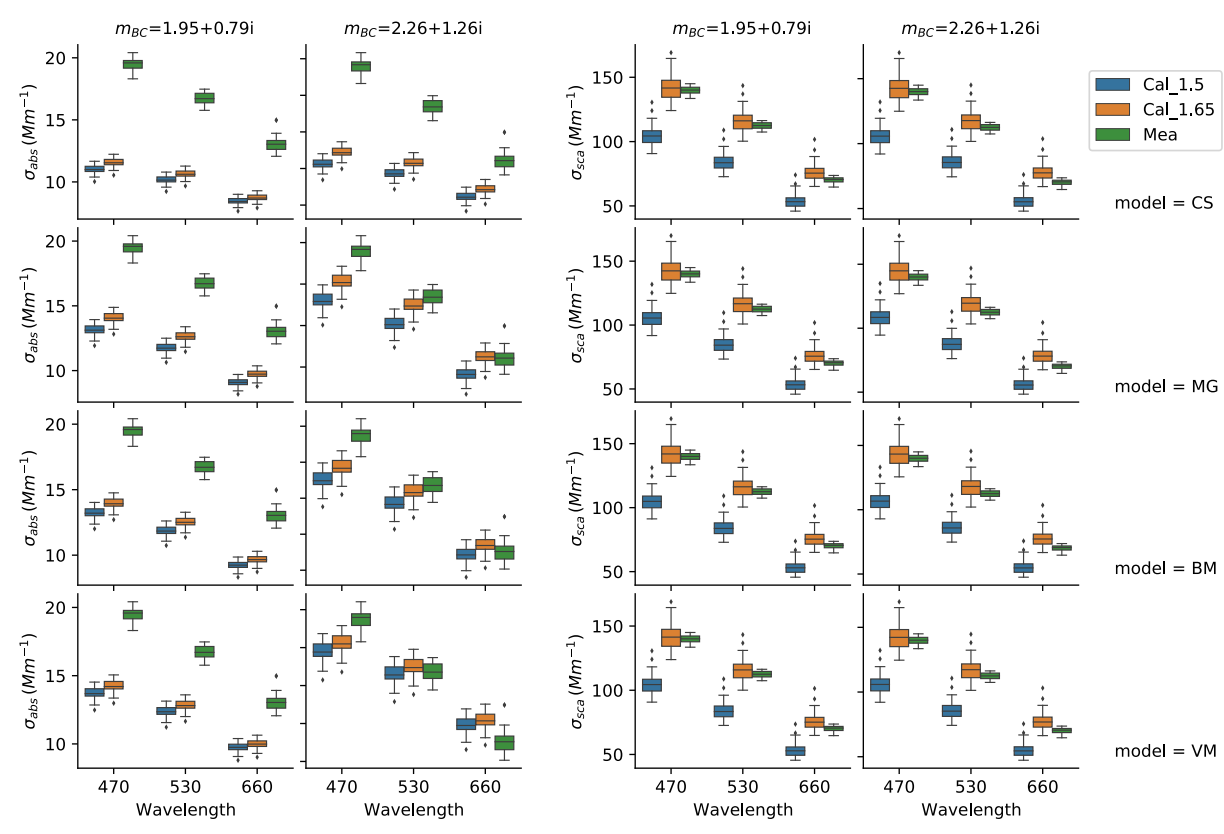

Figure 3: Modelled (blue and orange markers) and measured (green markers) absorption coefficients ( $\left.\sigma_{\text {abs}}\right)$ and scattering coefficients $\left(\sigma_{\text {sca }}\right)$ at PSAP wavelengths for RF06_1. Variables are modelled with two commonly used $m_{\mathrm{BC}}$ values (shown on the top) and two values of $m_{\mathrm{OA}}$ using the CS, MG, BG, and VM models (specified on the right). OA is

assumed to be non-absorbing with the refractive index $m_{\mathrm{OA}}$ equal to $1.5+0 \mathrm{i}$ (blue markers) and $1.65+0 i$ (orange markers), respectively. Values of $\sigma_{\text {sca }}$ measured by the nephelometer at 450,550 , and $700 \mathrm{~nm}$ are interpolated to PSAP wavelengths, 470, 530, and $660 \mathrm{~nm}$ using the scattering Ångström exponent (Section S3 in the supplement).

We introduce an effective refractive index of $B C, m_{e B C}$, to represent the refractive index of $B C$ and any other absorbing components at $\mathbf{6 6 0} \mathbf{n m}$ in this study. The $m_{\mathrm{eBC}}$ is defined as $m_{\mathrm{eBC}}=n_{\mathrm{eBC}}+\mathrm{i} k_{\mathrm{eBC}}$, where $n_{\mathrm{eBC}}$ and

$10 k_{\mathrm{eBC}}$ are the real and imaginary parts of $m_{\mathrm{eBC}}$, respectively. The $m_{\mathrm{eBC}}$ is proposed based on three considerations. Firstly, the numerical value selected for $m_{\mathrm{BC}}$ has a large impact on the absorption attributed to BC (Fig. 3 and Fig. S3), and hence on the estimated absorption by $\mathrm{BrC}$, but as note above, there is no consensus on the best value of $m_{\mathrm{BC}}$ yet. Secondly, the lack of measurements of possible absorbers other than $\mathrm{BC}$ and $\mathrm{BrC}$ such as magnetite makes it difficult to correctly estimate the $\mathrm{BrC}$ absorption, so approaches that take these components into consideration are required. Thirdly, aged $\mathrm{BrC}$ is usually considered to be non-absorbing at long visible wavelengths (Chen and Bond, 2010; Lack et al., 2012), thus we assume $m_{\mathrm{eBC}}$ does not include the absorptivity of $\mathrm{BrC}$ and therefore the $\mathrm{BrC}$ absorption can be differentiated from absorption from other substances. This assumption has not considered tar balls, which are ubiquitous in fresh plumes and absorbing at infrared 
wavelengths; considering the aging time of our samples, the absorption of tar balls is expected to be small or negligible (Sedlacek III et al., 2018; Adler et al., 2019; Li et al., 2019).

The $m_{\mathrm{eBC}}$ is named the effective refractive index of $\mathrm{BC}$ as it is supposed to be contributed mainly or entirely by $\mathrm{BC}$. The $m_{\mathrm{eBC}}$ would be the same as $m_{\mathrm{BC}}$ if the absorption at $660 \mathrm{~nm}$ is solely contributed by BC; however, if other absorbing components are present, the imaginary part $\left(k_{\mathrm{eBC}}\right)$ of $m_{\mathrm{eBC}}$ would be greater than that $\left(k_{\mathrm{BC}}\right)$ of $m_{\mathrm{BC}}$, the amount of which depends on the absorptivity and relative amount of these absorbers. The retrieval of $m_{\mathrm{eBC}}$ is illustrated in Fig. 2; the real refractive index of $\mathrm{OA}\left(n_{\mathrm{OA}}\right)$ is retrieved as well because it has an impact, albeit small, on the BC absorption calculation (Fig. 3 and Fig. S3). Note that OA is assumed to be non-absorbing with the imaginary refractive index $k_{\mathrm{OA}}=0$ in the whole calculation. We determined the values of $m_{\mathrm{eBC}}$ and $m_{\mathrm{OA}}$

10 by minimizing the sums of the squares of the relative differences between the measured and calculated scattering and absorption coefficients at $660 \mathrm{~nm}$ for each of the four models:

$$
\chi^{2}\left(m_{e B C}, m_{O A}\right)=\left(\frac{\sigma_{s c a, 660}^{c a l}-\sigma_{s c a, 660}^{m e a}}{\sigma_{s c a, 660}^{m e a}}\right)^{2}+\left(\frac{\sigma_{a b s, 660}^{c a l}-\sigma_{a b s, 660}^{m e a}}{\sigma_{a b s, 660}^{m e a}}\right)^{2}
$$

Values of $n_{\mathrm{eBC}}, k_{\mathrm{eBC}}$ and $n_{\mathrm{OA}}$ are varied from 1.5 to 4, 0.3 to 2.5 (Chylek et al., 2019; Taylor et al., 2020) and 1.35 to 1.7 (Lack and Cappa, 2010; Liu et al., 2013; Saleh et al., 2014; Moise et al., 2015), respectively - over greater range than those recorded in literature. Values of $\chi^{2} / N$ greater than $10 \%$ are excluded, where $\mathrm{N}$ stands for the total data number. The quantities $\sigma_{a b s, 660}^{c a l}$ and $\sigma_{a b s, 660}^{m e a}$ are the calculated and measured absorption coefficients at $660 \mathrm{~nm}$, respectively, and $\sigma_{s c a, 660}^{c a l}$ and $\sigma_{s c a, 660}^{m e a}$ are the calculated and measured scattering coefficients at $660 \mathrm{~nm}$, respectively, where $\sigma_{s c a, 660}^{m e a}$ is determined by interpolated using the scattering Ångström exponent from scattering coefficients measured by the nephelometer (Section S3 in the supplement). Only absorption is used in the calculation of $\chi^{2}$ for RF05_1 and RF05_2, as measured and simulated scattering coefficients are not comparable (discussed in detail in Section S1.2 in the supplement):

$$
\chi^{2}\left(m_{e B C}, m_{O A}\right)=\sum_{\lambda=660}\left(\frac{\sigma_{a b s, \lambda}^{c a l}-\sigma_{a b s, \lambda}^{m e a}}{\sigma_{a b s, \lambda}^{m e a}}\right)^{2}
$$

We assume the $m_{\mathrm{eBC}}$ and $m_{\mathrm{OA}}$ remain constant over the range of investigated wavelengths, i.e. 470-660 $\mathrm{nm}$, and calculate the absorption coefficients at 470 and $530 \mathrm{~nm}\left(\sigma_{a b s, 470}^{c a l}\right.$ and $\left.\sigma_{a b s, 530}^{c a l}\right)$ for each flight using the different models. The values of $m_{\mathrm{BC}}$ and $m_{\mathrm{OA}}$ are usually considered to be very weakly dependent on, or independent of, wavelength in the visible spectrum (e.g., Chang and Charalampopoulos, 1990; Moteki et al., 2010; Saleh et al., 2014). As will be discussed later in Section 3.1, absorbers that contribute to $m_{\mathrm{eBC}}$ besides $\mathrm{BC}$ are mainly regarded as magnetite, whose refractive index is generally invariant between wavelengths 470 and 660 $\mathrm{nm}$. Thus, the assumption of constant $m_{\mathrm{eBC}}$ and $m_{\mathrm{OA}}$ between 470 and $660 \mathrm{~nm}$ is reasonable in our study, although it may lead to underestimations of $\mathrm{BrC}$ absorption for highly aged particles, as discussed further in Section 3.2. In addition, the absorption by $\mathrm{BrC}$ may be slightly underestimated without incorporating tar balls into the calculation. As illustrated in Fig. 2, the absorption at shorter wavelengths is assumed to be determined by that 
from $\mathrm{BrC}$, and that from all other absorbing components, the latter of which is characterized entirely by $m_{\mathrm{eBC}}$.

Therefore, the absorption of $\mathrm{BrC}$ at wavelength $\lambda\left(\sigma_{\mathrm{abs}, \mathrm{BrC}, \lambda)}\right)$ can be calculated as the difference between measured absorption coefficients $\left(\sigma_{a b s, \lambda}^{m e a}\right)$ and the ones calculated with $m_{\mathrm{eBC}}\left(\sigma_{a b s, \lambda}^{c a l}\right)$ :

$$
\sigma_{a b s, B r c, \lambda}=\sigma_{a b s, \lambda}^{m e a}-\sigma_{a b s, \lambda}^{c a l}
$$

The quantity $R_{\mathrm{BrC}, \lambda}$, defined as

$$
R_{B r C, \lambda}=\sigma_{a b s, B r C, \lambda} / \sigma_{a b s, \lambda}^{m e a}
$$

5 is the fractional contribution of $\mathrm{BrC}$ to the total absorption at wavelength $\lambda$, which is assumed to be zero at 660 $\mathrm{nm}$ in our study. The mass absorption coefficient (MAC) of OA (MACOA, $\lambda$ ) at wavelength $\lambda$ can be determined

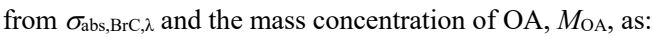

$$
M A C_{O A, \lambda}=\sigma_{a b s, B r C, \lambda} / M_{O A}
$$

Similarly, the mass absorption coefficient of $\mathrm{BC}(\mathrm{MAC} B \mathrm{BC})$ is defined as: $M A C_{B C}=\sigma_{a b s}^{m e a} / M_{B C}$, where $\sigma_{a b s}^{m e a}$ and $M_{\mathrm{BC}}$ represent the measured absorption coefficient and the mass concentration of $\mathrm{BC}$.

\section{Results and discussion}

\subsection{Effective refractive index of $\mathrm{BC}\left(m_{\mathrm{eBC}}\right)$}

In this section, we present and discuss the results of $m_{\mathrm{eBC}}$ derived from the aforementioned four models using the AMS, SP2, APS, and UHSAS data for each sample. The values of $k_{\mathrm{eBC}}$ for each sample determined by the various models are shown in Figure 4. Also shown in that figure is the mass ratio (MR) of non-BC to BC substance for BC-containing particles, calculated as $M R=\frac{\sum_{i}\left(D_{p, i}^{3}-D_{C, i}^{3}\right) * \rho_{B C-\text { free }}}{\sum_{i} D_{C, i}^{3} \rho_{B C}}$, where $D_{\mathrm{p}}$ and $D_{\mathrm{c}}$ are diameters of coated BC particles and mass-equivalent diameters of $\mathrm{BC}$ core, respectively. The $\mathrm{MR}_{100}$ is the MR for particles with $100 \mathrm{~nm}$ BC core only, i.e. $D_{\mathrm{c}}$ equals to $100 \mathrm{~nm}$. As stated in Section 2.3, values of $m_{\mathrm{eBC}}$ for RF05_1 and RF05_2 are constrained only by absorption coefficients with Eq. 9. To justify its feasibility, we derived $m_{\mathrm{eBC}}$ for other flights using Eq. 9 and found the differences are less than $5 \%$ for both the real and imaginary parts. No result for RF05_3 was obtained with CS model because no $m_{\mathrm{eBC}}$ value has been achieved in the retrieval.

The variation of $k_{\mathrm{eBC}}$ shows a similar pattern among different models (Fig. 4). Those values derived from the CS and VM models are the highest and lowest, respectively, consistent with modelling results for absorption in previous studies (e.g. Taylor et al. 2020), and those from the MG and BG models are between the other two and are very close to each other. The values of $k_{\mathrm{eBC}}$ for RF05_1, RF05_2, RF06_1, and RF06_2 from the CS model have greatly exceeded the largest $k_{\mathrm{BC}}$ of commonly used values of $m_{\mathrm{BC}}$ (grey shaded region in Fig. 4), determined by Moteki et al. (2010) for soot particles from an urban source, Tokyo. Except for RF10, little confidence can be placed in the value of $k_{\mathrm{eBC}}$ from the CS model, for two main reasons. First, the bulk MR for all samples is less than 2, and application of the CS model may be inappropriate for particles with such low MR values (Liu et al., 2017). Second, the TEM analysis found few core-shell structures (e.g., example of RF05_1 in 
Fig. 5) among all investigated samples, with most BC-containing particles composed of condensed BC nodules internally mixed with salts/organics (e.g., example of RF05_3 in Fig. 5) or aggregates attached to non-BC components (e.g., example of RF05_2 in Fig. 5). Figure 5 shows representative TEM images of different types of $\mathrm{BC}$-containing particles for each flight. Although a fair number of $\mathrm{BC}$ particles homogeneously mixed with salts

5 and OA were detected from TEM for RF10 (Fig. 5), which seems to resemble homogeneous models, this sample is thickly coated, with MR equal to 7.4 and $\mathrm{MR}_{100}$ equal to 22.5 , largely exceeded the threshold value of MR for the CS model specified in Liu et al. (2017). In addition, results of $\mathrm{BrC}$ contribution to the total absorption also suggest that the CS model for RF10 is more reasonable, which will be discussed in detail in Section 3.3.

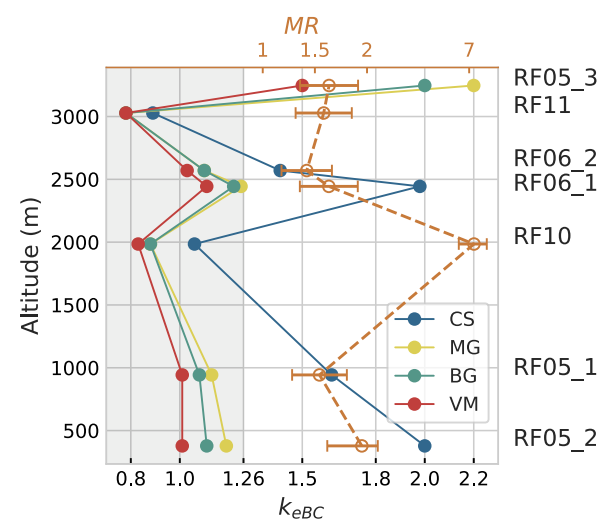

10 Figure 4: Values of $k_{\mathrm{eBC}}$ (closed dots) derived from different models and MR (orange open dots, top x-axis) for each flight. Error bars of MR represent $17 \%$ uncertainty. The top $\mathrm{x}$-axis is using the log scale. Grey shaded region for $\mathrm{k}_{\mathrm{eBC}}$ $<1.26$ marks the range of values of $k_{\mathrm{BC}}$ commonly used for BC. 


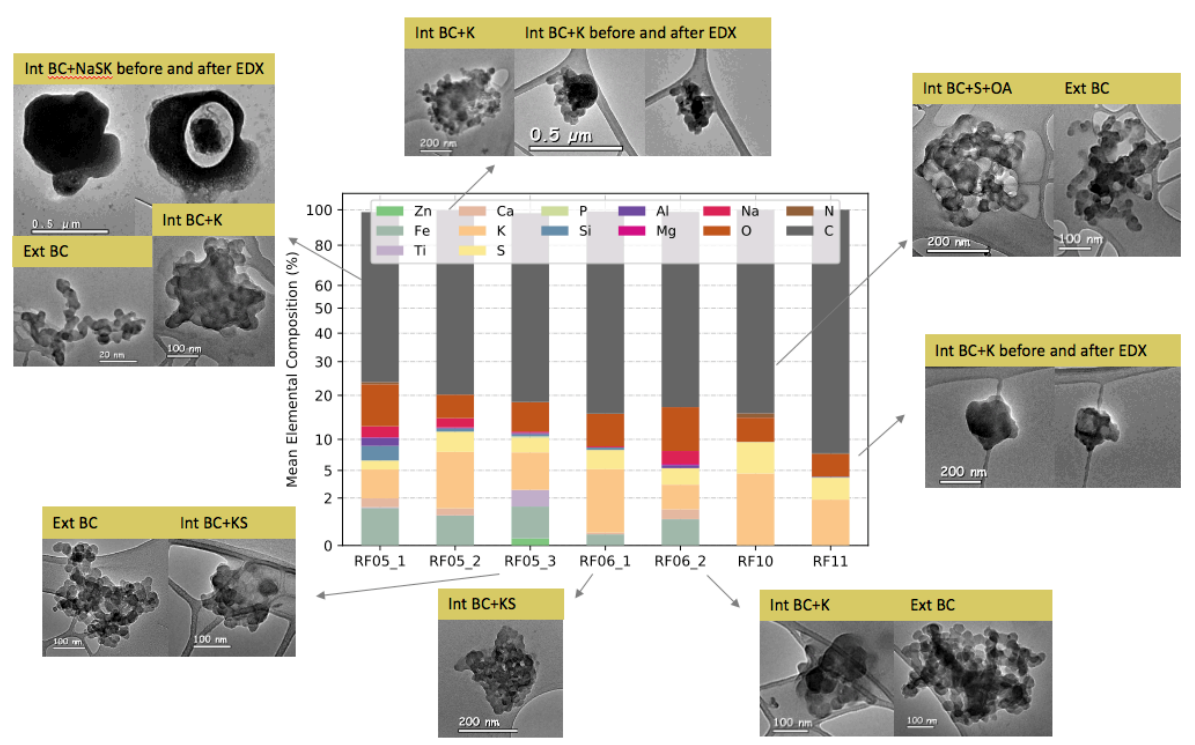

Figure 5: Elemental composition and representative microphysical images of different types of BC-containing particles from TEM analysis for each flight. Int BC and Ext BC represent internally and externally mixed BC particles, respectively. For example, Int $\mathrm{BC}+\mathrm{K}$ stands for internally mixed $\mathrm{BC}$ with potassium salts. The $\mathrm{y}$-axis uses a $\mathrm{x}^{1 / 2}$ scale.

As discussed in section 2.3, $m_{\mathrm{eBC}}$ should be the same as $m_{\mathrm{BC}}$ if the absorption at $660 \mathrm{~nm}$ arises only from $\mathrm{BC}$; otherwise, higher $k_{\mathrm{eBC}}$ values indicate larger contributions of absorbers other than $\mathrm{BC}$ at $660 \mathrm{~nm}$. The values of $k_{\mathrm{eBC}}$ for RF05_1, RF05_2, RF05_3, RF06_1, and RF06_2, for which iron (Fe) was detected from the TEMEDX (as shown in the bar chart in Fig. 5), are greater than those for RF10 and RF11, for which no iron was detected. Therefore, we suspect higher $k_{\mathrm{eBC}}$ values are related to iron oxides (FeOx) that absorbs at $660 \mathrm{~nm}$, which we suspect to be magnetite, based on the following three points. Firstly, magnetite absorbs strongly and uniformly over the visible spectrum with the imaginary refractive index ranging from 0.58 to 1.0 according to literature (Amaury et al., unpublished data, http://www.astro.uni-jena.de/Laboratory/OCDB/mgfeoxides.html; Ackerman and Toon, 1981; Zhang et al., 2015), and can thereby contribute to the high values of $k_{\mathrm{eBC}}$ at $660 \mathrm{~nm}$. Secondly, magnetite can be transformed at high temperatures from Fe(III), such as goethite and hematite (Till et al., 2015; Ito et al., 2018), which happen to be the two most abundant forms of FeOx in African dust (Formenti et al., 2014). Therefore, it is speculated that a part of the magnetite is converted from Fe(III) during biomass burning. Thirdly, magnetite can be emitted by anthropogenic combustion, such as steel manufacturing, oil combustion, and vehicle emissions (Liati et al., 2015; Ito et al., 2018; Kurisu et al., 2019). Its significance in radiative forcing and carbon cycle has been investigated and highlighted in recent studies (Moteki et al., 2017; Ito et al., 2018; Lamb et al.,

20 2021). Although there is no study on pyrogenic iron in sub-Saharan Africa yet, we speculate that anthropogenic combustion emissions in Africa, especially in coastal areas, may also contribute magnetite. 
Among all flights, RF05_3, collected at the uppermost aerosol layer (Fig. 4), is an exception, since the values of the absorption coefficient at $660 \mathrm{~nm}$ calculated with all four models are considerably smaller than the measured ones (Fig. S3). The MG, BG, and VM models yield $k_{\mathrm{eBC}}$ values greater than 1.5 , and no value was attained with the CS model. The MAC $\mathrm{CBC}_{\mathrm{BC}}$ of RF05 3 is the highest among all those investigated with values of $20.0 \pm 0.8,17.8 \pm 0.8$, and $14.3 \pm 0.7 \mathrm{~m}^{2} \mathrm{~g}^{-1}$ at 470,530 , and $660 \mathrm{~nm}$, respectively. The absorption enhancement, $E_{\mathrm{Abs}}$, defined as the ratio of $\mathrm{MAC}_{\mathrm{BC}}$ to the value for uncoated $\mathrm{BC}$ reported by Bond and Bergstrom (2006), is $2.3 \pm 0.1$ for all three wavelengths. To the best of our knowledge, except for modelling or laboratory studies of thickly coated particles (Bond et al., 2006; Jacobson, 2012; Peng et al., 2016), such high values of $E_{\text {Abs, }}$ particularly at long visible wavelengths, are rarely reported in field measurements (Cui et al., 2016). Taylor et al. (2020) presented relatively high $\mathrm{MAC}_{\mathrm{BC}}$ values of $20 \pm 4,15 \pm 3$, and $12 \pm 2 \mathrm{~m}^{2} \mathrm{~g}^{-1}$ at 405,514 , and $655 \mathrm{~nm}$, respectively and an $E_{\mathrm{Abs}}$ of $1.85 \pm 0.45$ for the CLARIFY 2017; however, these values are still smaller than those for RF05_3. Particles in CLARIFY 2017 are universally thickly coated, with median MR values of 8-12, and are therefore believed to have a largely enhanced lensing effect, which is not the case for RF05_3, which for which MR (Fig. 4) was equal to 1.6 and $\mathrm{MR}_{100}$ was equal to 5.3. The calculated absorption coefficient for RF05_3 at $660 \mathrm{~nm}$, using $m_{\mathrm{BC}}$ of $1.95+0.79 \mathrm{i}$ and $m_{\mathrm{OA}}$ of $1.65+0 \mathrm{i}$, was only $59 \%$ of the measured absorption coefficient (Fig. S3), implying that the remaining $41 \%$ of absorption was contributed by other absorbers. This huge absorption from other absorbers in this flight may indicate a much larger amount of magnetite compared to other flights. In addition, we noticed titanium (Ti) on the particles analyzed from RF05_3. Formenti et al. (2014) found the mineral dust in western Africa consists mainly of clays, quartz, iron, and titanium oxides, which together represent at least $92 \%$ of the dust mass. Although titanium oxides are not absorbing, several forms of Ti have been reported to strongly absorb at visible wavelengths (Pflüger and Fink, 1997; Palm et al., 2018). Therefore, we suspect this large absorption may also be related to absorbing titanium compounds.

\subsection{Mass absorption coefficient of OA (MACOA)}

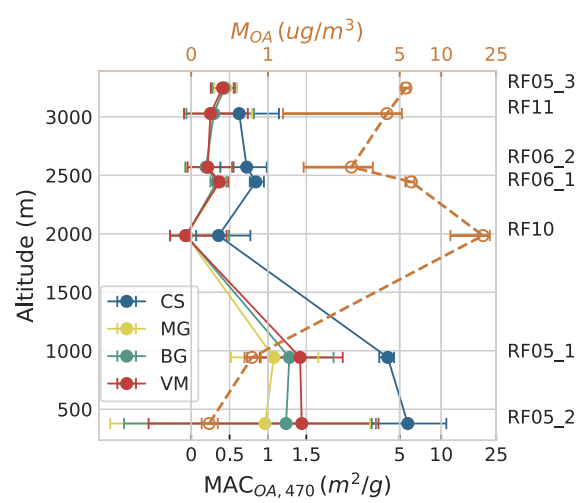


Figure 6: Values of $\mathrm{MAC}_{\mathrm{OA}, 470}$ (closed dots) derived using different models and mass concentrations of $\mathrm{OA}, \mathrm{M}_{\mathrm{OA}}$ (orange open dots, top $\mathrm{x}$-axis), for each flight. Error bars represent the $10^{\text {th }}$ and $90^{\text {th }}$ percentile. The scale of both $\mathrm{x}$ axes is symmetric log.

Values of MACOA,470 calculated from Eq. 12 using the different models are shown in Fig. 6. The values of MACOA,470 from the three homogeneous models were fairly close to each other; while MACOA,470 from the CS model was much greater, highlighting the importance of the proper model treatment. From Section 3.1, results of RF10 from the CS model, and other flights from homogeneous models, are more plausible, with values of MACOA,470 for RF05_3, RF06_1, RF06_2, RF10, and RF11 ranging from $0.25 \pm 0.34 \mathrm{~m}^{2} / \mathrm{g}$ to $0.43 \pm 0.12 \mathrm{~m}^{2} / \mathrm{g}$. Our result at $470 \mathrm{~nm}$ is slightly lower or generally comparable to the value $0.31 \pm 0.09 \mathrm{~m}^{2} / \mathrm{g}$ at $405 \mathrm{~nm}$ for highly aged aerosols sampled downwind of ORACLES in CLARIFY 2017 campaign (Taylor et al., 2020), suggesting BrC bleaching during transport considering our result is at a much longer wavelength (Che et al., 2021).

RF05_1 and RF05_2, whose particles are equally or even more aged than those in CLARIFY, showed unexpectedly high $\mathrm{MAC}_{\mathrm{OA}, 470}$ values of $1.18 \pm 0.54 \mathrm{~m}^{2} / \mathrm{g}$ and $1.07 \pm 1.60 \mathrm{~m}^{2} / \mathrm{g}$, respectively. Although $\mathrm{M}_{\mathrm{OA}}$ for these samples are low (Fig. 6), measurements from all instruments are within the detection limit, which would argue that the values are valid. Wang et al. (2018) used airborne measurements to constrain their global model and found the best MACOA to represent the measurements is $1.33 \mathrm{~m}^{2} / \mathrm{g}$ for freshly emitted BB OA at $365 \mathrm{~nm}$. Lin et al. (2017) investigated relatively fresh $\mathrm{BB}$ aerosols subject to atmospheric processes during a night-long $\mathrm{BB}$ event in an urban environment and got a MAC of $0.9 \mathrm{~m}^{2} / \mathrm{g}$ for water extractable $\mathrm{BrC}$ at $470 \mathrm{~nm}$ under the peak BB episode. Our values of MAC $\mathrm{OA}, 470_{0}$ for RF05_1 and RF05_2 are higher than those for much fresher BB aerosols, which seems unrealistic, as $\mathrm{BrC}$ bleaching is expected to occur during transport. One possible explanation is that secondary $\mathrm{BrC}$ formation occurred, perhaps through aqueous-phase chemistry during transport (Hems et al., 2021), for RF05_1 and RF05_2, which were sampled in or close to the MBL with higher RHs. Saleh et al. (2013) reported that secondary $\mathrm{BrC}$ can be more absorbing than primary $\mathrm{BrC}$ at short visible wavelengths; however, to the best of our knowledge, such high MAC for secondary BrC have not been documented (Kasthuriarachchi et al., 2020).

As we assume a constant $m_{\mathrm{eBC}}$ over the investigated spectrum, i.e. $470-660 \mathrm{~nm}$, if there are some components with strong absorption at short visible but not at long visible wavelengths, the $m_{\mathrm{eBC}}$ would be underestimated at shorter wavelengths and therefore MACOA would be overestimated. Hematite, whose imaginary refractive index ranges from 0 to 1.0 at $470 \mathrm{~nm}$ and 0 to 0.4 at $670 \mathrm{~nm}$ (Zhang et al., 2015; Go et al., 2021), is the second most abundant FeOx in western African dust (Formenti et al., 2014). Particles in RF05_1 and RF05_2 experienced approximately 6 days of transport and thus may have had more opportunities to mix with hematite and therefore lead to an overestimation of MACOA. While lacking measurements on these absorbers, it is difficult to verify our speculation. A modified SP2 has been reported by (Yoshida et al., 2016) that can discriminate black- 

investigations.

\subsection{Contribution of $\mathrm{BrC}$ to total absorption $\left(\boldsymbol{R}_{\mathrm{BrC}}\right)$}

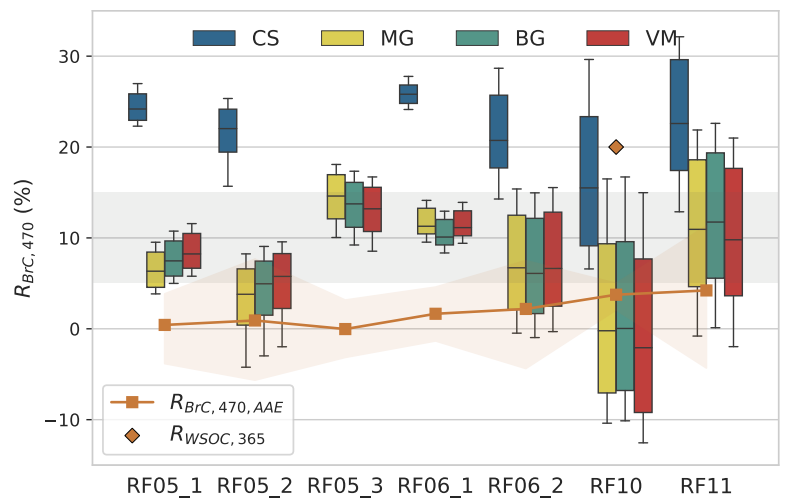

5 Figure 7: Contribution of $\mathrm{BrC}$ to the total absorption obtained from optical closure approach in this study (boxes, $\left.R_{\mathrm{BrC}, 470}\right)$ and from the $\mathrm{AAE}$ attribution method (orange squares, $\boldsymbol{R}_{\mathrm{BrC}, 470, \mathrm{AAE})}$ at $470 \mathrm{~nm}$. The grey zone indicates the $R_{\mathrm{BrC}, 470}$ range of 5-15\% in this study. Orange shades of $R_{\mathrm{BrC}, 470, \mathrm{AAE}}$ represent the $10^{\text {th }}$ and $90^{\text {th }}$ percentile. The orange diamond is the contribution of WSOC to the total absorption, $\boldsymbol{R}_{\mathrm{WSOC}, 365}$ (personal communication).

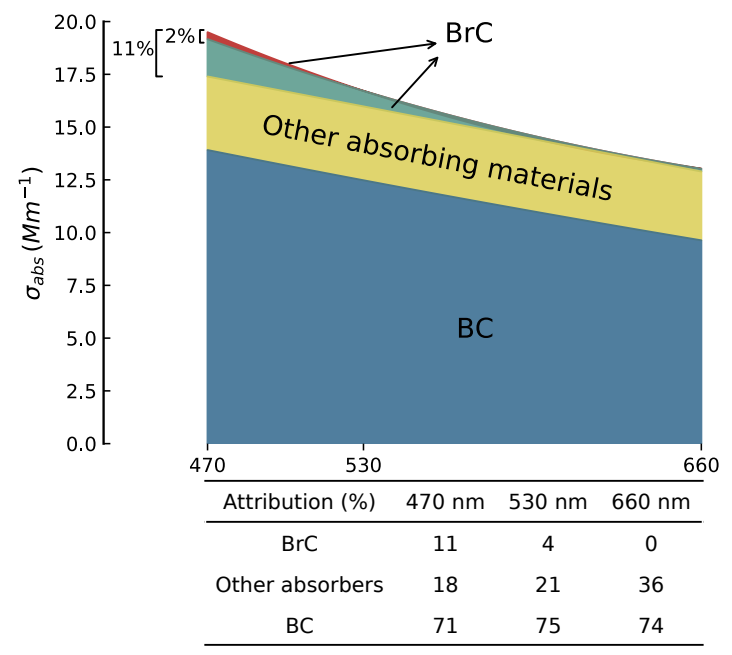

10 Figure 8: Illustration of the attribution of absorption for RF06_1. Blue area represents the absorption of BC, calculated with $m_{\mathrm{BC}}=1.95+0.79 \mathrm{i}$ and $m_{\mathrm{OA}}=1.65+0 \mathrm{i}$ using $\mathrm{BG}$ model. The upper border of the yellow region represents absorption coefficients calculated with corresponding $m_{e B C}$ and $m_{\mathrm{OA}}$ for RF06_1 using BG model assuming non-absorbing OA; the yellow area illustrates the absorption by absorbing components besides $\mathrm{BC}$ and $\mathrm{BrC}$, calculated as the difference 
between the two absorption coefficients calculated by the BG model using $\boldsymbol{m}_{\mathrm{eBC}}$ and $\boldsymbol{m}_{\mathrm{BC}}$, respectively. The upper border of the red region is drawn with measured absorption coefficients at 470,530 , and $660 \mathrm{~nm}$. The red region stands for the BrC absorption coefficient calculated from the AAE attribution method with Eq. 14. The $2 \%$ and $11 \%$ are the proportions of $\mathrm{BrC}$ at $470 \mathrm{~nm}$ estimated from the AAE attribution method and our optical closure method, respectively.

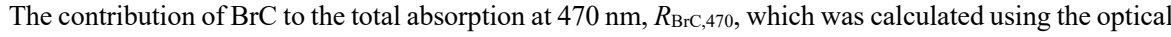
closure method from Eq. 11, is shown in Fig. 7. Similar to the results for MACOA, the MG, BG, and VM models

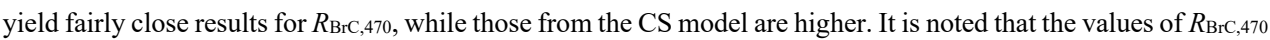
from MG, BG, and VM models at $470 \mathrm{~nm}$ for RF10 are near zero, which is unrealistic for the following three reasons. Firstly, RF10 was sampled after approximately 40 hours of transport; although there are considerable photobleaching and oxidative whitening of $\mathrm{BrC}$ when removed from its source for a day or more, it is unlikely that $\mathrm{BrC}$ will be completely bleached with a $40 \mathrm{~h}$ aging time (Hems et al., 2021). Secondly, samples in this study with similar aging times, i.e. RF05_3, RF06_1, RF06_2, and RF11, all showed a much greater contribution of $\mathrm{BrC}$ to absorption. Finally, Nenes et al. (personal communication) reported the contribution of water-soluble $\mathrm{BrC}$ to the total absorption at $365 \mathrm{~nm}$ of $20 \%$. As our RF10 was measured 10 min earlier at a similar location in the plume and no distinct changes were observed in either the meteorological conditions or aerosol properties, we expect the $\mathrm{AAE}$ of $\mathrm{BrC}$ derived from these two results to be within the range of those from literature. Since the absorption coefficient of $\mathrm{BrC}$ at $365 \mathrm{~nm}$ is unknown, we assumed it to be $20 \%$ of the measured absorption coefficient at $470 \mathrm{~nm}$ and calculated the $\mathrm{AAE}$ of $\mathrm{BrC}$ between 365 and $470 \mathrm{~nm}$ with the calculated $\mathrm{BrC}$ absorption coefficient at $470 \mathrm{~nm}$ from homogeneous models. This $\mathrm{AAE}$ is much lower than the actual AAE for $\mathrm{BrC}$ as the $\mathrm{BrC}$ absorption coefficient at $365 \mathrm{~nm}$ is greatly underestimated, but it is still well above the upper limit of the AAE range, 2-11, reported in the literature (Laskin et al., 2015). As discussed in Section 3.1, the values of $R_{\mathrm{BrC}, 470}$ for RF10 from the CS model and RF05_1, RF05_2, RF05_3, RF06_1, RF06_2, and RF11 from homogeneous models are more plausible than those from the CS model. As discussed in Section 3.2, particles of RF05_1 and RF05_2 may contain hematite, in which cases their $\mathrm{R}_{\mathrm{BrC}, 470}$ may have been overestimated. Generally, in our study, the $R_{\mathrm{BrC}, 470}$ ranges from $\sim 5-15 \%$ at $470 \mathrm{~nm}$ (grey zone in Fig. 7). This value is lower than the contribution of 13$26 \%$ at $500 \mathrm{~nm}$ for relatively fresh OA in the wood smoke from Kirchstetter and Thatcher (2012). Comparing to the result of $\sim 11 \%$ at $405 \mathrm{~nm}$ for highly aged aerosols from CLARIFY 2017, which were sampled downwind of ORACLES with 4-8 d aging time, our result is generally comparable while under a much longer wavelength, implying the bleaching of $\mathrm{BrC}$ during transport (Taylor et al., 2020; Che et al., 2021).

We calculated the contribution of $\mathrm{BrC}$ to the total absorption using the $\mathrm{AAE}$ attribution method $\left(R_{\mathrm{BrC}, 470, \mathrm{AAE}}\right)$ and compared it with that from our optical closure method $\left(R_{\mathrm{BrC}, 470)}\right)$ In the $\mathrm{AAE}$ attribution method, the absorption coefficient of $\mathrm{BC}$ at the investigated wavelength (470 $\mathrm{nm}$ in our case) is determined by 
extrapolating the absorption coefficient at a longer wavelength (530 $\mathrm{nm}$ in our case) with the AAE of BC. For example, in this study, the average AAE at 530/660 wavelength pair (AAE $530 / 660)$ for all flights is $0.93 \pm 0.16$, within the range expected for BC. Thus, we assume that the absorption coefficients at $530 \mathrm{~nm}\left(\sigma_{a b s, 530}^{m e a}\right)$ and $\mathrm{AAE}_{530 / 660}$ have no significant contribution from $\mathrm{BrC}$ and that the $\mathrm{AAE}$ for $\mathrm{BC}$ is independent of wavelength. The

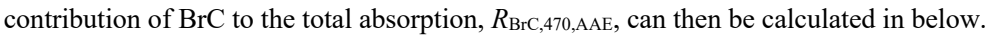

$$
\begin{gathered}
R_{B r C, 470, A A E}=1-\frac{\sigma_{a b s, 470}^{c a l, A A E}}{\sigma_{a b s, 470}^{m e a}} \\
\sigma_{a b s, 470}^{c a l, A A E}=\sigma_{a b s, 530}^{m e a}\left(\frac{530}{470}\right)^{A A E_{530 / 660}} \\
A A E_{530 / 660}=-\frac{\ln \left(\sigma_{a b s, 530}^{m e a} / \sigma_{a b s, 660}^{m e a}\right)}{\ln (530 / 660)}
\end{gathered}
$$

$\sigma_{a b s, 470}^{m e a}, \sigma_{a b s, 530}^{m e a}$, and $\sigma_{a b s, 660}^{m e a}$ represent the measured absorption coefficients at 470, 530, and $660 \mathrm{~nm}$, respectively. $\sigma_{a b s, 470}^{c a l, A A E}$ is the absorption coefficient calculated from the AAE attribution method at $470 \mathrm{~nm}$. Actually, this assumption is not always true as the AAE varies with both the wavelength and core size and coating thickness of BC particles (Lack and Cappa, 2010; Wang et al., 2016). The results of $R_{\mathrm{BrC}, 470, \mathrm{AAE}}$ are shown in Fig.

107 , with averages of all flights below $5 \%$, roughly a factor of three smaller than $R_{\mathrm{BrC}, 470 .}$

The extreme underestimation from the AAE attribution method is mainly due to the fact that the AAE and absorption coefficients used in this method are not derived from $\mathrm{BC}$ alone, but include contributions from other absorbing substances. Take RF06_1 as an example, the contribution of BrC derived from the AAE attribution method is $2 \%$, approximately a factor of five smaller than that from our optical closure method with the BG model, 11\% (Fig. 7 and 8). As illustrated in Fig. 8, the absorption coefficient at $530 \mathrm{~nm}$ used in Eq. 14 and 15 includes the contribution of $\mathrm{BrC}$, which accounts for $4 \%$ of the total absorption, and that of absorbers beyond $\mathrm{BC}$ and $\mathrm{BrC}$, which accounts for $21 \%$. Note this attribution is based on the $\mathrm{BC}$ absorption coefficient calculated from the BG model with $m_{\mathrm{BC}}=1.95+0.79 \mathrm{i}$, which will vary with the value of $m_{\mathrm{BC}}$. If we remove the $4 \%$ BrC from $\sigma_{a b s, 530}^{m e a}$ in Eq. 14, the contribution would increase to 6\%, two times larger than $2 \%$, indicating that even though $\mathrm{BrC}$ may exist as a small portion at the long wavelength, its impact on the AAE attribution method can be substantial. Thus, we recommend that application of any optical properties-based attribution method to use absorption coefficients at the longest possible wavelength to minimize the influence of $\mathrm{BrC}$, and in the meanwhile, to account for potential contributions from other absorbing materials.

\section{Conclusions}

We investigated the contribution of $\mathrm{BrC}$ to the total absorption with different models utilizing measurements from ORACLES 2018 field campaign. An effective $\mathrm{BC}$ refractive index, $m_{\mathrm{eBC}}=n_{\mathrm{eBC}}+\mathrm{i} k_{\mathrm{eBC}}$, that was constrained by scattering and absorption measurements to account for all absorbing components at $660 \mathrm{~nm}$, was introduced in this study. Most of the values derived for $k_{\mathrm{BC}}$ were greater than the commonly used $k_{\mathrm{BC}}$ values, 
suggesting contributions from absorbing materials besides $\mathrm{BC}$ at $660 \mathrm{~nm}$. TEM-EDX single particle analysis further suggests that these absorbers might include $\mathrm{FeOx}$ that absorbs at long visible wavelengths, i.e. magnetite, as Fe is only present for flights with large values of $k_{\mathrm{eBC}}$. RF05_3 yielded the largest values of $k_{\mathrm{eBC}}$, approximately $40 \%-140 \%$ greater than that of other flights, implying a greater contribution of absorbers besides $\mathrm{BC}$ to the total absorption at $660 \mathrm{~nm}$ than other flights, which could be due to a larger amount of magnetite in these samples or the result of possible absorbing titanium compounds, which are present on this filter.

As refractive indices of $\mathrm{BC}$ and magnetite are generally constant over the range of wavelengths considered, i.e. 470 and $660 \mathrm{~nm}$, we assumed $m_{\mathrm{eBC}}$ to be independent of wavelength and calculated MACOA and

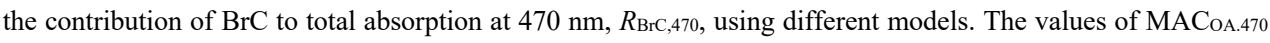
and $R_{\mathrm{BrC}, 470}$ from the three homogeneous mixing models were fairly close to each other, while those from the CS model were much higher, underscoring the importance of proper model treatment. The values of MACOA.470 and contribution of $\mathrm{BrC}$ to the total absorption, $R_{\mathrm{BrC}, 470}$, from the $\mathrm{CS}$ model for $\mathrm{RF} 10$ and homogeneous models for other flights are found to be more plausible, based on the morphology from TEM images, MR values from SP2, and the validation of the WSOC results. The values of $R_{\mathrm{BrC}, 470}$ ranged from $\sim 5-15 \%$, with MACoA.470 varying between $0.25 \pm 0.34 \mathrm{~m}^{2} \mathrm{~g}^{-1}$ and $0.43 \pm 0.12 \mathrm{~m}^{2} \mathrm{~g}^{-1}$ for the various flights. Values from our results were generally comparable with MACOA of $0.31 \pm 0.09 \mathrm{~m}^{2} \mathrm{~g}^{-1}$ and $R_{\mathrm{BrC}}$ of $\sim 11 \%$ at $405 \mathrm{~nm}$ for highly aged aerosols from CLARIFY 2017, which were sampled downwind of ORACLES with 4-8 d aging time, while under a much longer wavelength, i.e. $470 \mathrm{~nm}$, implying the bleaching of $\mathrm{BrC}$ during transport. High $\mathrm{MAC}_{\mathrm{OA}, 470}$ values of $1.18 \pm 0.54$ and $1.07 \pm 1.60 \mathrm{~m}^{2} \mathrm{~g}^{-1}$ were observed for RF05_1 and RF05_2, respectively, which is suspected to be due to the presence of hematite, an abundant $\mathrm{FeOx}$ in African dust, which may have mixed with the $\mathrm{BC}$ particles during the $\sim 6 \mathrm{~d}$ transport. Measurements of a modified SP2 that can distinguish between hematite and magnetite and obtain FeOx concentrations is highly recommended.

Contribution of $\mathrm{BrC}$ to the total absorption obtained from the $\mathrm{AAE}$ attribution method, $R_{\mathrm{BrC}, 470, \mathrm{AAE}}$, were calculated and compared to that from our optical closure method. $R_{\mathrm{BrC}, 470, \mathrm{AAE}}$ is generally $<5 \%$, approximately a factor of three smaller than those from our optical closure method. From the absorption attribution of RF06_1 as an example, we found this underestimation is mainly due to the influence of absorbers besides $\mathrm{BC}$ in parameters used in this approach. Thus, when applying optical properties-based attribution methods, it is recommended to use the absorption coefficient at the longest possible wavelength to minimise the influence of $\mathrm{BrC}$ and to account for other absorbers in the meanwhile.

30

Acknowledgements. The authors would like to thank the ORACLES team and the postdoctoral fellowship funding from Tel Aviv University, Department of Exact Sciences. Arthur J. Sedlacek III and Ernie R. Lewis thank the Scientific Focus Area (SFA) Science Plan program that is supported by the Office of Biological and 
Environmental Research in the Department of Energy, Office of Science, through the United States Department of Energy Contract No. DE-SC0012704 to Brookhaven National Laboratory.

Data availability. Airborne measurements are available via the digital object identifier provided under ORACLES

Science Team reference: https://doi.org/10.5067/Suborbital/ORACLES/P3/2018_V2.

Author contributions. MSR and LZ developed the ideas for the direction of the paper. MSR, AJS, EL, AD, JPW, PF, SGH, and AN carried out the airborne measurements. MSR, HC, CD, AJS, EL, AD, JPW, SGH, and AN processed the aircraft data. LZ and HC performed the data analysis. LZ prepared the paper with inputs and comments from all co-authors.

Competing interests. The author declares that there is no conflict of interest.

Special issue statement. This article is part of the special issue "New observations and related modeling studies of the aerosol-cloud-climate system in the Southeast Atlantic and southern Africa regions (ACP/AMT interjournal SI)". It is not associated with a conference.

\section{References}

Ackerman, T. P. and Toon, O. B.: Absorption of visible radiation in atmosphere containing mixtures of absorbing and nonabsorbing particles, Appl. Opt., 20, 3661-3668, https://doi.org/10.1364/AO.20.003661, 1981.

20 Adler, G., Wagner, N. L., Lamb, K. D., Manfred, K. M., Schwarz, J. P., Franchin, A., Middlebrook, A. M., Washenfelder, R. A., Womack, C. C., Yokelson, R. J., and Murphy, D. M.: Evidence in biomass burning smoke for a light-absorbing aerosol with properties intermediate between brown and black carbon, Aerosol Sci. Technol., 53, 976-989, https://doi.org/10.1080/02786826.2019.1617832, 2019.

Bond, T. C. and Bergstrom, R. W.: Light Absorption by Carbonaceous Particles: An Investigative Review, Aerosol Sci. Technol., 40, 27-67, https://doi.org/10.1080/02786820500421521, 2006.

Bond, T. C., Habib, G., and Bergstrom, R. W.: Limitations in the enhancement of visible light absorption due to mixing state, J. Geophys. Res. Atmospheres, 111, https://doi.org/10.1029/2006JD007315, 2006.

Bond, T. C., Doherty, S. J., Fahey, D. W., Forster, P. M., Berntsen, T., DeAngelo, B. J., Flanner, M. G., Ghan, S., Kärcher, B., Koch, D., Kinne, S., Kondo, Y., Quinn, P. K., Sarofim, M. C., Schultz, M. G., Schulz, M., 30 Venkataraman, C., Zhang, H., Zhang, S., Bellouin, N., Guttikunda, S. K., Hopke, P. K., Jacobson, M. Z., Kaiser, J. W., Klimont, Z., Lohmann, U., Schwarz, J. P., Shindell, D., Storelvmo, T., Warren, S. G., and Zender, C. S.: 
Bounding the role of black carbon in the climate system: A scientific assessment, J. Geophys. Res. Atmospheres, 118, 5380-5552, https://doi.org/10.1002/jgrd.50171, 2013.

Brown, H., Liu, X., Feng, Y., Jiang, Y., Wu, M., Lu, Z., Wu, C., Murphy, S., and Pokhrel, R.: Radiative effect and climate impacts of brown carbon with the Community Atmosphere Model (CAM5), Atmospheric Chem.

Phys., 18, 17745-17768, https://doi.org/10.5194/acp-18-17745-2018, 2018.

Che, H., Segal-Rozenhaimer, M., Zhang, L., and Dang, C.: Transport and aging of biomass burning aerosols in the South-eastern Atlantic Ocean, Commun. Earth Environ., Under review, 2021.

Chen, Y. and Bond, T. C.: Light absorption by organic carbon from wood combustion, Atmospheric Chem. Phys., 10, 1773-1787, https://doi.org/10.5194/acp-10-1773-2010, 2010.

10 Chylek, P., Lee, J. E., Romonosky, D. E., Gallo, F., Lou, S., Shrivastava, M., Carrico, C. M., Aiken, A. C., and Dubey, M. K.: Mie Scattering Captures Observed Optical Properties of Ambient Biomass Burning Plumes Assuming Uniform Black, Brown, and Organic Carbon Mixtures, J. Geophys. Res. Atmospheres, 124, 11406 11427, https://doi.org/10.1029/2019JD031224, 2019.

Cui, X., Wang, X., Yang, L., Chen, B., Chen, J., Andersson, A., and Gustafsson, Ö.: Radiative absorption

15 enhancement from coatings on black carbon aerosols, Sci. Total Environ., 551-552, 51-56, https://doi.org/10.1016/j.scitotenv.2016.02.026, 2016.

Dang, C., Segal-Rozenhaimer, M., Che, H., Zhang, L., Formenti, P., Taylor, J., Dobracki, A., Purdue, S., Wong, P.-S., Nenes, A., Sedlacek, A., Coe, H., Redemann, J., Zuidema, P., and Haywood, J.: Biomass burning and marine aerosol processing over the southeast Atlantic Ocean: A TEM single particle analysis, Atmospheric Chem. Phys.

Discuss., 1-30, https://doi.org/10.5194/acp-2021-724, 2021.

Feng, Y., Ramanathan, V., and Kotamarthi, V. R.: Brown carbon: a significant atmospheric absorber of solar radiation?, Atmospheric Chem. Phys., 13, 8607-8621, https://doi.org/10.5194/acp-13-8607-2013, 2013.

Formenti, P., Caquineau, S., Desboeufs, K., Klaver, A., Chevaillier, S., Journet, E., and Rajot, J. L.: Mapping the physico-chemical properties of mineral dust in western Africa: mineralogical composition, Atmospheric Chem.

Phys., 14, 10663-10686, https://doi.org/10.5194/acp-14-10663-2014, 2014.

Go, S., Lyapustin, A., Schuster, G. L., Choi, M., Ginoux, P., Chin, M., Kalashnikova, O., Dubovik, O., Kim, J., Silva, A. da, Holben, B., and Reid, J. S.: Inferring iron oxides species content in atmospheric mineral dust from DSCOVR EPIC observations, Atmospheric Chem. Phys. Discuss., https://doi.org/10.5194/acp-2021-599, 2021.

Gysel, M., Crosier, J., Topping, D. O., Whitehead, J. D., Bower, K. N., Cubison, M. J., Williams, P. I., Flynn, M.

30 J., McFiggans, G. B., and Coe, H.: Closure study between chemical composition and hygroscopic growth of aerosol particles during TORCH2, Atmospheric Chem. Phys., 7, 6131-6144, https://doi.org/10.5194/acp-7-61312007, 2007. 
Hems, R. F., Schnitzler, E. G., Liu-Kang, C., Cappa, C. D., and Abbatt, J. P. D.: Aging of Atmospheric Brown Carbon Aerosol, ACS Earth Space Chem., 5, 722-748, https://doi.org/10.1021/acsearthspacechem.0c00346, 2021.

Ito, A., Lin, G., and Penner, J. E.: Radiative forcing by light-absorbing aerosols of pyrogenetic iron oxides, Sci. Rep., 8, 7347, https://doi.org/10.1038/s41598-018-25756-3, 2018.

5 Jacobson, M. Z.: Investigating cloud absorption effects: Global absorption properties of black carbon, tar balls, and soil dust in clouds and aerosols, J. Geophys. Res. Atmospheres, 117, https://doi.org/10.1029/2011JD017218, 2012.

Jo, D. S., Park, R. J., Lee, S., Kim, S.-W., and Zhang, X.: A global simulation of brown carbon: implications for photochemistry and direct radiative effect, Atmospheric Chem. Phys., 16, 3413-3432, https://doi.org/10.5194/acp-16-3413-2016, 2016.

Kasthuriarachchi, N. Y., Rivellini, L.-H., Adam, M. G., and Lee, A. K. Y.: Light Absorbing Properties of Primary and Secondary Brown Carbon in a Tropical Urban Environment, Environ. Sci. Technol., 54, 10808-10819, https://doi.org/10.1021/acs.est.0c02414, 2020.

Kirchstetter, T. W. and Thatcher, T. L.: Contribution of organic carbon to wood smoke particulate matter 15 absorption of solar radiation, Atmospheric Chem. Phys., 12, 6067-6072, https://doi.org/10.5194/acp-12-60672012, 2012.

Kuang, Y., He, Y., Xu, W., Zhao, P., Cheng, Y., Zhao, G., Tao, J., Ma, N., Su, H., Zhang, Y., Sun, J., Cheng, P., Yang, W., Zhang, S., Wu, C., Sun, Y., and Zhao, C.: Distinct diurnal variation in organic aerosol hygroscopicity and its relationship with oxygenated organic aerosol, Atmospheric Chem. Phys., 20, 865-880, https://doi.org/10.5194/acp-20-865-2020, 2020.

Kurisu, M., Adachi, K., Sakata, K., and Takahashi, Y.: Stable Isotope Ratios of Combustion Iron Produced by Evaporation in a Steel Plant, ACS Earth Space Chem., 3, 588-598, https://doi.org/10.1021/acsearthspacechem.8b00171, 2019.

Lack, D. A. and Cappa, C. D.: Impact of brown and clear carbon on light absorption enhancement, single scatter albedo and absorption wavelength dependence of black carbon, Atmospheric Chem. Phys., 10, 4207-4220, https://doi.org/10.5194/acp-10-4207-2010, 2010.

Lack, D. A. and Langridge, J. M.: On the attribution of black and brown carbon light absorption using the Ångström exponent, Atmospheric Chem. Phys., 13, 10535-10543, https://doi.org/10.5194/acp-13-10535-2013, 2013.

30 Lack, D. A., Langridge, J. M., Bahreini, R., Cappa, C. D., Middlebrook, A. M., and Schwarz, J. P.: Brown carbon and internal mixing in biomass burning particles, Proc. Natl. Acad. Sci., 109, 14802-14807, https://doi.org/10.1073/pnas.1206575109, 2012. 
Lamb, K. D., Matsui, H., Katich, J. M., Perring, A. E., Spackman, J. R., Weinzierl, B., Dollner, M., and Schwarz, J. P.: Global-scale constraints on light-absorbing anthropogenic iron oxide aerosols, Npj Clim. Atmospheric Sci., 4, 1-12, https://doi.org/10.1038/s41612-021-00171-0, 2021.

Laskin, A., Laskin, J., and Nizkorodov, S. A.: Chemistry of Atmospheric Brown Carbon, Chem. Rev., 115, 4335-

Li, C., He, Q., Schade, J., Passig, J., Zimmermann, R., Meidan, D., Laskin, A., and Rudich, Y.: Dynamic changes in optical and chemical properties of tar ball aerosols by atmospheric photochemical aging, Atmospheric Chem. Phys., 19, 139-163, https://doi.org/10.5194/acp-19-139-2019, 2019.

Liati, A., Pandurangi, S. S., Boulouchos, K., Schreiber, D., and Arroyo Rojas Dasilva, Y.: Metal nanoparticles in

10 diesel exhaust derived by in-cylinder melting of detached engine fragments, Atmos. Environ., 101, 34-40, https://doi.org/10.1016/j.atmosenv.2014.11.014, 2015.

Lin, P., Bluvshtein, N., Rudich, Y., Nizkorodov, S. A., Laskin, J., and Laskin, A.: Molecular Chemistry of Atmospheric Brown Carbon Inferred from a Nationwide Biomass Burning Event, Environ. Sci. Technol., 51, 11561-11570, https://doi.org/10.1021/acs.est.7b02276, 2017.

15 Liu, C., Chung, C. E., Yin, Y., and Schnaiter, M.: The absorption Ångström exponent of black carbon: from numerical aspects, Atmospheric Chem. Phys., 18, 6259-6273, https://doi.org/10.5194/acp-18-6259-2018, 2018.

Liu, D., Taylor, J. W., Young, D. E., Flynn, M. J., Coe, H., and Allan, J. D.: The effect of complex black carbon microphysics on the determination of the optical properties of brown carbon, Geophys. Res. Lett., 42, 613-619, https://doi.org/10.1002/2014GL062443, 2015.

20 Liu, D., Whitehead, J., Alfarra, M. R., Reyes-Villegas, E., Spracklen, D. V., Reddington, C. L., Kong, S., Williams, P. I., Ting, Y.-C., Haslett, S., Taylor, J. W., Flynn, M. J., Morgan, W. T., McFiggans, G., Coe, H., and Allan, J. D.: Black-carbon absorption enhancement in the atmosphere determined by particle mixing state, Nat. Geosci., 10, 184-188, https://doi.org/10.1038/ngeo2901, 2017.

Moteki, N., Kondo, Y., and Nakamura, S.: Method to measure refractive indices of small nonspherical particles: Application to black carbon particles, J. Aerosol Sci., 41, 513-521, https://doi.org/10.1016/j.jaerosci.2010.02.013, 2010.

Moteki, N., Adachi, K., Ohata, S., Yoshida, A., Harigaya, T., Koike, M., and Kondo, Y.: Anthropogenic iron oxide aerosols enhance atmospheric heating, Nat. Commun., 8, 15329, https://doi.org/10.1038/ncomms15329, 2017.

30 Palm, K. J., Murray, J. B., Narayan, T. C., and Munday, J. N.: Dynamic optical properties of metal hydrides, ACS Photonics, 5, 4677-4686, https://doi.org/10.1021/acsphotonics.8b01243, 2018. 
Peng, J., Hu, M., Guo, S., Du, Z., Zheng, J., Shang, D., Levy Zamora, M., Zeng, L., Shao, M., Wu, Y.-S., Zheng, J., Wang, Y., Glen, C. R., Collins, D. R., Molina, M. J., and Zhang, R.: Markedly enhanced absorption and direct radiative forcing of black carbon under polluted urban environments, Proc. Natl. Acad. Sci., 113, 4266-4271, https://doi.org/10.1073/pnas.1602310113, 2016.

Pflüger, J. and Fink, J.: Handbook of Optical Constants of Solids, Academic Press, 293-310 pp., 1997.

Pistone, K., Redemann, J., Doherty, S., Zuidema, P., Burton, S., Cairns, B., Cochrane, S., Ferrare, R., Flynn, C., Freitag, S., Howell, S. G., Kacenelenbogen, M., LeBlanc, S., Liu, X., Schmidt, K. S., Sedlacek III, A. J., SegalRozenhaimer, M., Shinozuka, Y., Stamnes, S., van Diedenhoven, B., Van Harten, G., and Xu, F.: Intercomparison of biomass burning aerosol optical properties from in situ and remote-sensing instruments in ORACLES-2016, Atmospheric Chem. Phys., 19, 9181-9208, https://doi.org/10.5194/acp-19-9181-2019, 2019.

Redemann, J., Wood, R., Zuidema, P., Doherty, S. J., Luna, B., LeBlanc, S. E., Diamond, M. S., Shinozuka, Y., Chang, I. Y., Ueyama, R., Pfister, L., Ryoo, J., Dobracki, A. N., da Silva, A. M., Longo, K. M., Kacenelenbogen, M. S., Flynn, C. J., Pistone, K., Knox, N. M., Piketh, S. J., Haywood, J. M., Formenti, P., Mallet, M., Stier, P., Ackerman, A. S., Bauer, S. E., Fridlind, A. M., Carmichael, G. R., Saide, P. E., Ferrada, G. A., Howell, S. G., Freitag, S., Cairns, B., Holben, B. N., Knobelspiesse, K. D., Tanelli, S., L’Ecuyer, T. S., Dzambo, A. M., Sy, O. O., McFarquhar, G. M., Poellot, M. R., Gupta, S., O’Brien, J. R., Nenes, A., Kacarab, M. E., Wong, J. P. S., Small-Griswold, J. D., Thornhill, K. L., Noone, D., Podolske, J. R., Schmidt, K. S., Pilewskie, P., Chen, H., Cochrane, S. P., Sedlacek, A. J., Lang, T. J., Stith, E., Segal-Rozenhaimer, M., Ferrare, R. A., Burton, S. P., Hostetler, C. A., Diner, D. J., Platnick, S. E., Myers, J. S., Meyer, K. G., Spangenberg, D. A., Maring, H., and Gao, L.: An overview of the ORACLES (ObseRvations of Aerosols above CLouds and their intEractionS) project: aerosol-cloud-radiation interactions in the Southeast Atlantic basin, Atmospheric Chem. Phys. Discuss., 1-82, https://doi.org/10.5194/acp-2020-449, 2020.

Saleh, R., Robinson, E. S., Tkacik, D. S., Ahern, A. T., Liu, S., Aiken, A. C., Sullivan, R. C., Presto, A. A., Dubey, M. K., Yokelson, R. J., Donahue, N. M., and Robinson, A. L.: Brownness of organics in aerosols from biomass burning linked to their black carbon content, Nat. Geosci., 7, 647-650, https://doi.org/10.1038/ngeo2220, 2014.

Saleh, R., Marks, M., Heo, J., Adams, P. J., Donahue, N. M., and Robinson, A. L.: Contribution of brown carbon and lensing to the direct radiative effect of carbonaceous aerosols from biomass and biofuel burning emissions, $\mathrm{J}$. Geophys. Res. Atmospheres, 120, 10,285-10,296, https://doi.org/10.1002/2015JD023697, 2015.

Sedlacek III, A. J., Buseck, P. R., Adachi, K., Onasch, T. B., Springston, S. R., and Kleinman, L.: Formation and 30 evolution of tar balls from northwestern US wildfires, Atmospheric Chem. Phys., 18, 11289-11301, https://doi.org/10.5194/acp-18-11289-2018, 2018.

Taylor, J. W., Wu, H., Szpek, K., Bower, K., Crawford, I., Flynn, M. J., Williams, P. I., Dorsey, J., Langridge, J. M., Cotterell, M. I., Fox, C., Davies, N. W., Haywood, J. M., and Coe, H.: Absorption closure in highly aged biomass burning smoke, Atmospheric Chem. Phys., https://doi.org/10.5194/acp-2020-333, 2020. 
Till, J. L., Guyodo, Y., Lagroix, F., Morin, G., and Ona-Nguema, G.: Goethite as a potential source of magnetic nanoparticles in sediments, Geology, 43, 75-78, https://doi.org/10.1130/G36186.1, 2015.

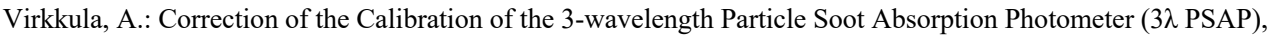
Aerosol Sci. Technol., 44, 706-712, https://doi.org/10.1080/02786826.2010.482110, 2010.

5 Wang, J., Nie, W., Cheng, Y., Shen, Y., Chi, X., Wang, J., Huang, X., Xie, Y., Sun, P., Xu, Z., Qi, X., Su, H., and Ding, A.: Light absorption of brown carbon in eastern China based on 3-year multi-wavelength aerosol optical property observations and an improved absorption Ångström exponent segregation method, Atmospheric Chem. Phys., 18, 9061-9074, https://doi.org/10.5194/acp-18-9061-2018, 2018 a.

Wang, L., Li, Z., Tian, Q., Ma, Y., Zhang, F., Zhang, Y., Li, D., Li, K., and Li, L.: Estimate of aerosol absorbing 10 components of black carbon, brown carbon, and dust from ground-based remote sensing data of sun-sky radiometers, J. Geophys. Res. Atmospheres, 118, 6534-6543, https://doi.org/10.1002/jgrd.50356, 2013.

Wang, X., Heald, C. L., Sedlacek, A. J., de Sá, S. S., Martin, S. T., Alexander, M. L., Watson, T. B., Aiken, A. C., Springston, S. R., and Artaxo, P.: Deriving brown carbon from multiwavelength absorption measurements: method and application to AERONET and Aethalometer observations, Atmospheric Chem. Phys., 16, 1273312752, https://doi.org/10.5194/acp-16-12733-2016, 2016.

Wang, X., Heald, C. L., Liu, J., Weber, R. J., Campuzano-Jost, P., Jimenez, J. L., Schwarz, J. P., and Perring, A. E.: Exploring the observational constraints on the simulation of brown carbon, Atmospheric Chem. Phys., 18, 635-653, https://doi.org/10.5194/acp-18-635-2018, 2018 b.

van der Werf, G. R., Randerson, J. T., Giglio, L., Collatz, G. J., Mu, M., Kasibhatla, P. S., Morton, D. C., DeFries, R. S., Jin, Y., and van Leeuwen, T. T.: Global fire emissions and the contribution of deforestation, savanna, forest, agricultural, and peat fires (1997-2009), Atmospheric Chem. Phys., 10, 11707-11735, https://doi.org/10.5194/acp-10-11707-2010, 2010.

Wong, J. P. S., Tsagkaraki, M., Tsiodra, I., Mihalopoulos, N., Violaki, K., Kanakidou, M., Sciare, J., Nenes, A., and Weber, R. J.: Atmospheric evolution of molecular-weight-separated brown carbon from biomass burning, Atmospheric Chem. Phys., 19, 7319-7334, https://doi.org/10.5194/acp-19-7319-2019, 2019.

Yoshida, A., Moteki, N., Ohata, S., Mori, T., Tada, R., Dagsson-Waldhauserová, P., and Kondo, Y.: Detection of light-absorbing iron oxide particles using a modified single-particle soot photometer, Aerosol Sci. Technol., 50, 1-4, https://doi.org/10.1080/02786826.2016.1146402, 2016.

Zhang, X. L., Wu, G. J., Zhang, C. L., Xu, T. L., and Zhou, Q. Q.: What is the real role of iron oxides in the 30 optical properties of dust aerosols?, Atmospheric Chem. Phys., 15, 12159-12177, https://doi.org/10.5194/acp-1512159-2015, 2015. 